\title{
Studies on the Biology of the Red Sea Bream Chrysophrys major. I. Temperature Tolerance
}

\author{
N. Y. S. Woo and A. C. Y. Fung \\ Department of Biology, The Chinese University of Hong Kong, Shatin, N. T., Hong Kong
}

\begin{abstract}
The red sea bream Chrysophrys major is a widely cultured marine teleost. Experiments were therefore conducted to define its temperature tolerance characteristics, in an attempt to improve the management of the species. Upper and lower incipient lethal temperatures were estimated by exposing fish acclimated to different temperatures to a constant shock temperature for $48 \mathrm{~h}$. Both upper and lower incipient lethals increased with elevation of acclimation temperature. The ultimate upper and lower lethal temperatures, which could not be further increased or decreased by acclimation, were $32^{\circ}$ and $5.5^{\circ} \mathrm{C}$, respectively. Construction of a temperature tolerance polygon from these data indicates a thermal tolerance of $527.8^{\circ} \mathrm{C}^{2}$ for the red sea bream. These findings suggest problems for the culture of the species at high summer water temperatures.
\end{abstract}

\section{INTRODUCTION}

The red sea bream Chrysophrys major Temminck and Schlegel is. a marine teleost (Family Sparidae) which is widely distributed and cultured along the shallow coastal waters of Hong Kong. Knowledge of various aspects of its physiology would contribute significantly to the management of this species. However, a detailed study on the general physiology of the red sea bream is lacking, except for a series of documentations on some aspects of its nutrition (e. g. Sakamoto and Yone, 1978a) and starvation (Sakamoto and Yone, 1978b; Sakamoto et al., 1978). The authors therefore initiated a series of studies on the biology of the red sea bream. The present communication is the first of a series of papers describing the results of this investigation.

Although Hong Kong lies to the south of the Tropic of Cancer, local waters exhibit a marked seasonal variation in temperature. The mean local sea-surface temperature is about $29^{\circ} \mathrm{C}$ in late summer (August); in shallow impounded areas even higher temperatures are not uncommon (Williamson, 1970). In February, the sea surface temperature may be as low as $16^{\circ} \mathrm{C}$ (Williamson, 1970). In the face of such a seasonal temperature variation knowledge of the temperature tolerance characteristics of this species is highly desirable. The present study aims to define the degree of eurythermicity of Chrysophrys major. For a review on temperature effects on fishes consult 'Marine Ecology', Volume I: Brett (1970).

\section{MATERIALS AND METHODS}

Underyearling Chrysophrys major, weighing between 10 and $40 \mathrm{~g}$ (length: $30-60 \mathrm{~mm}$ ) were obtained directly from a sea-pen through a commercial supplier. They were acclimated to laboratory conditions at $9^{\circ}$. $14^{\circ}, 20^{\circ}$ and $28{ }^{\circ} \mathrm{C}$ in well-aerated seawater $(28 \% \mathrm{~S})$ aquaria. The acclimation temperature was held as constant as possible $\left( \pm 1 \mathrm{C}^{\circ}\right)$ using immersion coolers (FTS Systems) and heaters (Haake). Fish were acclimated to their final acclimation temperature slowly $\left(1-2 \mathrm{C}^{\circ} \mathrm{d}^{-1}\right)$ and were kept at the final acclimation temperature for a period of at least 2 weeks prior to experimentation. A total of 300 individuals were used. The fish were fed ground fish meat ad lib. during the acclimation period. The food was withheld $1 \mathrm{~d}$ before the beginning of experiments.

A series of well-aerated water baths (20 l) was set up at various temperatures $\left( \pm 0.5 \mathrm{C}^{\circ}\right)$ to determine the upper and lower incipient lethal temperatures (Fry et al., 1942). Groups of fish were abruptly transferred from the acclimation temperature to various test temperatures. The fish were kept in the shock baths for a period of $48 \mathrm{~h}$ as recommended by Fry (1971) and Venables et al. (1978). The \% mortality was recorded at the end of the observation period. Fish were considered dead upon loss of equilibrium followed by cessation of swimming and opercular activity (Venables et al., 1978). Fish exhibiting these phenomena did not recover when placed in either cooler or warmer water.

The $\%$ mortality of fish at each shock temperature 
was plotted against the acclimation temperature to obtain a series of survival curves. The temperature at which $50 \%$ of the fish died within 48 h was found from the curves by interpolation and was taken as the incipient lethal temperature $\left(\mathrm{LT}_{50}\right)$. The incipient lethal temperature was plotted against the acclimation temperature to obtain the temperature tolerance polygon (Fry et a1., 1942; Fry, 1964, 1971; Brett, 1970).

\section{RESULTS}

A plot of the \% mortality of red sea breams at $23^{\circ}-35^{\circ} \mathrm{C}$ after acclimation to $9^{\circ}, 14^{\circ}, 20^{\circ}$ and $28^{\circ} \mathrm{C}$ is shown in Figure 1. The upper incipient lethal temperatures for fish adapted to $9^{\circ}, 14^{\circ}, 20^{\circ}$ and $28^{\circ} \mathrm{C}$ were found by interpolation to be $24^{\circ}, 27.2^{\circ}, 30.5^{\circ}$ and $31.6^{\circ} \mathrm{C}$, respectively. All fish regardless of acclimation temperature could not survive for more than $24 \mathrm{~h}$ at $32^{\circ} \mathrm{C}$. This temperature was taken to be the ultimate upper lethal temperature as defined by Fry (1971).

A similar plot of the \% mortality of sea breams at $5^{\circ}-17^{\circ} \mathrm{C}$ after acclimation to $9^{\circ}, 14^{\circ}, 20^{\circ}$ and $28^{\circ} \mathrm{C}$ is given in Figure 2. The lower incipient lethal temperatures for fish adapted to $9^{\circ}, 14^{\circ}, 20^{\circ}$ and $28^{\circ} \mathrm{C}$ were $6.5^{\circ}$, $7.5^{\circ}, 11.5^{\circ}$ and $15.5^{\circ} \mathrm{C}$, respectively. The ultimate lower lethal temperature was reached at $5.5^{\circ} \mathrm{C}$.

Based on these data, a temperature tolerance polygon was constructed (Fig. 3). The area enclosed by the trapezoid was found to be $527.8^{\circ} \mathrm{C}^{2}$. The upper lethal temperature of the red sea bream increased $2 \mathrm{C}^{\circ}$ for every $3 \mathrm{C}^{\circ}$ increase in acclimation temperature from $5.5^{\circ}$ to $20.5^{\circ} \mathrm{C}$. Above $20.5^{\circ} \mathrm{C}$, the upper lethal temperature only increased $1 \mathrm{C}^{\circ}$ for a $8 \mathrm{C}^{\circ}$ increase in acclimation temperature, culminating at the ultimate lethal of $32^{\circ} \mathrm{C}$.

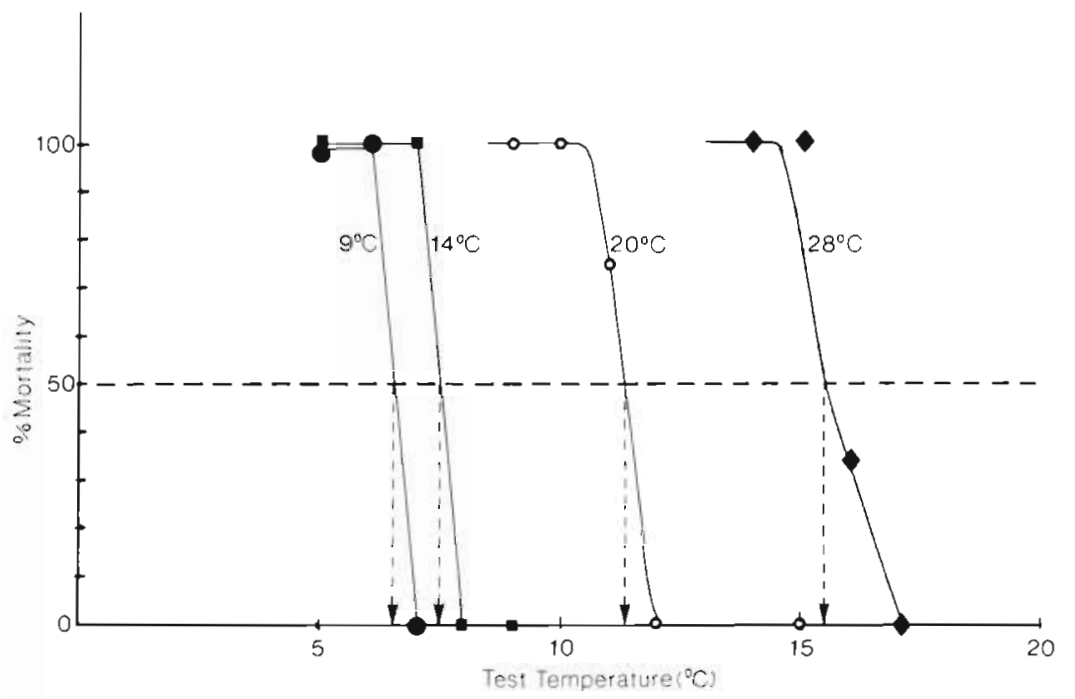

Fig. 1. Chrysophrys major. Percent mortality at $22^{\circ}$ to $35^{\circ} \mathrm{C}$ after acclimation to $9^{\circ}, 14^{\circ}, 20^{\circ}$ and $28^{\circ} \mathrm{C}$, respectively. The upper incipient lethal temperatures were determined by interpolation

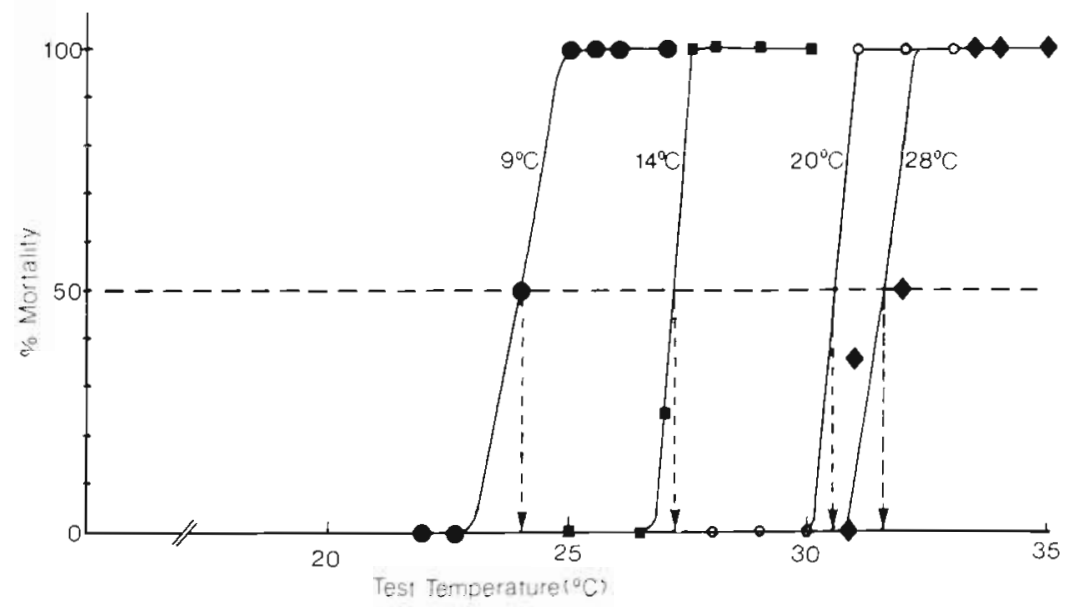

Fig. 2. Chrysophrys major. Percent mortality at $5^{\circ}$ to $17^{\circ} \mathrm{C}$ after acclimation to $9^{\circ}, 14^{\circ}, 20^{\circ}$ and $28^{\circ} \mathrm{C}$, respectively. The lower incipient lethal temperatures were determined by interpolation 


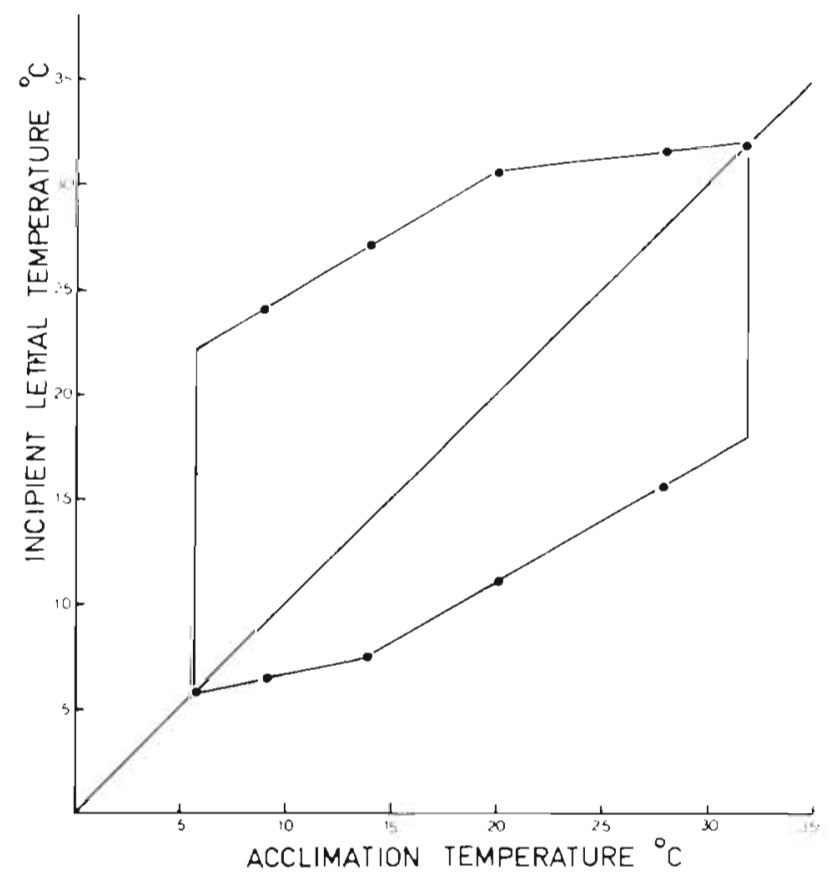

Fig. 3. Chrysophrys major. Temperature tolerance diagram showing the relationship between incipient lethal temperature and acclimation temperature

Similarly, the lower incipient lethal temperature increased with increasing acclimation temperature. From $9^{\circ}$ to $32^{\circ} \mathrm{C}$, the line joining the lower lethal temperatures is straight with a slope of $5 / 8$. Below $9^{\circ} \mathrm{C}$ acclimation temperature, the lower lethal increased only by $1 \mathrm{C}^{\circ}$ for every $4 \mathrm{C}^{\circ}$ increase in acclimation temperature.

\section{DISCUSSION}

It has been well established that acclimation of fish to different temperatures is accompanied by changes in the temperature compatible with life (for details consult 'Marine Ecology', Volume 1: Brett, 1970; Fry, 1971; Altman and Dittmer, 1974). The present data showed that both the upper and lower lethal temperatures of Chrysophrys major increase significantly with elevation of acclimation temperature, in agreement with all previous findings (e. g. Cocking, 1959; Venables et al., 1978). However, the rate at which the upper and lower incipient lethal temperatures change with variations in acclimation temperature is different for different species. The upper incipient lethal of the roach (Cocking, 1959), and goldfish (Fry et al., 1942) increases about $1 \mathrm{C}^{\circ}$ for each $3 \mathrm{C}^{\circ}$ rise in acclimation temperature but that of the speckled trout increases at a 1 to 7 ratio (Fry et al., 1946). A difference of $3 \mathrm{C}^{\circ}$ in acclimation temperature results in $2 \mathrm{C}^{\circ}$ change in the lower lethal of the goldfish (Fry et al., 1942). In the puffer, both the upper and lower lethals increase approximately $2 \mathrm{C}^{\circ}$ for every $5 \mathrm{C}^{\circ}$ rise in the acclimation temperature (Hoff and Westman, 1966). Our data obtained for the red sea bream indicate that lethal temperatures change with acclimation temperature at a steep slope; according to Fry et al. (1946), this implies a limited thermal tolerance for the species.

This statement is supported by the construction of the temperature tolerance diagram (Fig. 3) which defines the zone of tolerance (Cocking, 1959; Fry, 1971). In this study, the thermal tolerance of the red sea bream was found to be $527.8^{\circ} \mathrm{C}^{2}$. This is very low when compared with a temperature tolerance of $625^{\circ} \mathrm{C}^{2}$ obtained for the speckled trout (Fry et al., 1946), $770{ }^{\circ} \mathrm{C}^{2}$ for the roach (Cocking, 1959) and $1220^{\circ} \mathrm{C}^{2}$ for the goldfish (Fry et al., 1942). A compilation of temperature tolerance data for 23 different species can be found in the review of Brett (1956). Brett's table indicates that Chrysophrys major can be grouped among one of the least eurythermal species concerned. The thermal tolerance of $C$. major was found to be of the same order as that of the salmons (Brett, 1952; 1956) which are well known to be very sensitive to temperature changes.

Our data suggest that the red sea bream cannot attain maximal growth in the local waters of Hong Kong, at least not in summer. Growth of the red sea bream has been observed to be markedly influenced by water temperature (Kitazima, 1969). The average sea-surface temperature in late summer is about $29^{\circ} \mathrm{C}$; this is very close to the ultimate lethal of $32^{\circ} \mathrm{C}$. The situation is aggravated by the local practice of culturing the fish in cages floating on the surface waters of semi-impounded inlets. Although the sea surface temperature rarely exceeds the ultimate lethal of $32{ }^{\circ} \mathrm{C}$, growth, development and reproduction can be expected to be poor at temperatures near the lethal.

Within the tolerance polygon (limits of survival), polygons of smaller area for growth and reproduction can be envisaged (Fry, 1971). In fact, spawning of the red sea bream has been observed within the range of $15^{\circ}-22^{\circ} \mathrm{C}$ (Harada, 1969). This corroborates the observation that Chrysophrys major usually exhibits poor growth and high mortality in summer (Fung and Woo, unpublished). In mid-winter (February), the lowest average sea surface temperature is about $18^{\circ} \mathrm{C}$ which lies just in the middle of the temperature tolerance polygon. Such a winter temperature should not pose any threat to red sea breams (Fujita, 1969).

We therefore suggest a lowering of the cages to greater water depths in summer; this should allow the fish to grow at temperatures further away from their ultimate lethal. The technical and economic problems associated with such manipulation are presently being actively pursued. 
Acknowledgement. The authors wish to thank Mr K. C. Au for his help in preparing the illustrations.

\section{LITERATURE CITED}

Altman, P. L., Dittmer, D. S. (1974). Biology data book, Vol. 2, 2nd ed., Federation of American Societies for Experimental Biology, Bethesda, Maryland, pp. 799-803

Brett, J. R. (1952). Temperature tolerance in young Pacific salmon genus Oncorhynchus. J. Fish. Res. Bd Can. 9: 265-323

Brett, J. R. (1956). Some principles in the thermal requirements of fishes. Quat. Rev. Biol. 31: 75-87

Brett, J. R. (1970). Temperature: animals: fishes. In: Kinne, O. (ed.) Marine ecology, Vol. 1. Wiley-Interscience, London, pp. 515-560

Cocking, A. W. (1959). The effects of high temperatures on roach (Rutilus rutilus). I. The effects of constant high temperatures. J. exp. Biol. 36: 203-215

Fry, F. E. J. (1964). Animals in aquatic environments: fishes. In: Dill, D. B., Adolph, E. F., Wilber, C. G. (eds) Handbook of physiology, Sect 4. Am. Physiol. Soc., Wash. D.C., pp. $715-728$

Fry, F. E. J. (1971). The effect of environmental factors on the physiology of fish. In: Hoar, W. S., Randall, D. J. (eds) Fish physiology, Vol. 6. Academic Press, New York, London, pp. $1-98$
Fry, F. E. J., Brett, J. R., Clawson, G. H. (1942). Lethal limits of temperature for young goldfish. Revue can. Biol. 1: 50-56

Fry, F. E. J., Hart, J. S., Walker, K. F. (1946). Lethal temperature relations for a sample of young speckled trout, Salvelinus fontinalis. Univ. Toronto Stud. biol. Ser. 54: 9-35

Fujita, S. (1969). Symposium on culture and propagation of sea breams. II-2. Discussion. Bull. Jap. Soc. scient. Fish. 35: $562-607$

Harada, T. (1969). Symposium on culture and propagation of sea breams. I-3. Parent fish for obtaining ripe eggs. Bull. Jap. Soc. scient. Fish 35: 562-607

Hoff, J..G., Westman, J. R. (1966). The temperature tolerances of three species of marine fishes. J. mar. Res. 24: 131-140

Kitazima, T. (1969). Symposium on culture and propagation of sea breams. II-1. Problems on sea bream culture. Bull. Jap. Soc. scient. Fish. 35: 562-607

Sakamoto, S., Yone, Y. (1978a), Requirement of red sea bream for dietary Na and K. J. Fac. Agric. Kyushu Univ. 23: 79-84

Sakamoto, S., Yone, Y. (1978b). Effect of starvation on hematological characteristics, and the contents of chemical components and activities of enzymes in blood serum of red sea bream. J. Fac. Agric. Kyushu Univ. 23: 63-69

Sakamoto, S., Furuichi, M., Yone, Y. (1978). Effect of starvation on organ weight and chemical component of red sea bream. J. Fac. Agric. Kyushu Univ. 23: 71-77

Venables, B. J., Fitzpatrick, L. C., Pearson, W. D. (1978). Acclimation temperature and temperature tolerance in fingerling largemouth bass (Micropterus salmoides). Environ. Pollut. 17: 161-165

Williamson, G. R. (1970). Hydrography and weather of the Hong Kong fishing grounds. Hong Kong Fish. Bull. 1: 43-87 